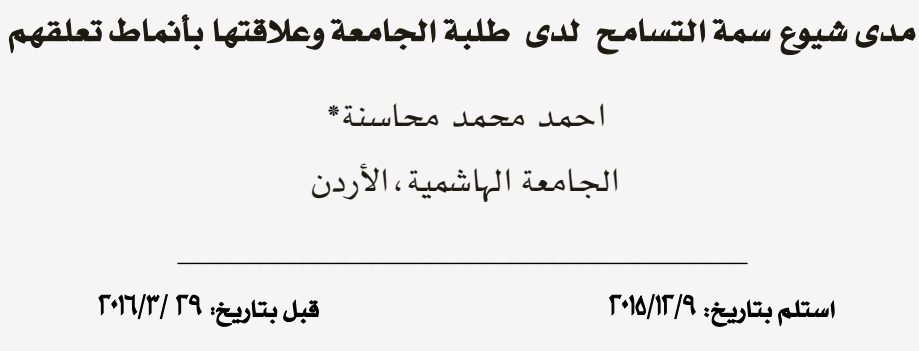

ملخص: هدفت هذه الدراسة إلى التعرف على مدى شيوع سهة التسامح لدى طلبة الجامعة وعلاقتها بأنهاط تعلقهم, كما هدفت الدراسة إلى معرفة إذا كان ثمة اختلاف هِ شيوع سمة التسامح تعزى لمتغير الجنس، والتخصص الأكاديهي والمستوى الدراسي. وتكونت عينة

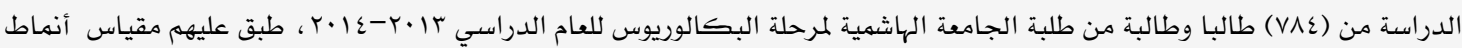
التعلق ومقياس لسمة التسامح. وقد أظهرت نتائج الدراسة أن شيوع سمة التسامح جاءت بدرجة متوسطة، وعدم وجود فروق ذات دلالة إحصائية وِّ شيوع سمة التسامع تعزى لمتغير الجنس، كها أظهرت نتائج الدراسة وجود فروق ذات دلالة إحصائية ِِّ شيوع سمة التسامح تعزى لمتغير التخصص الأكاديهي لصالح طلبة الكليات الإنسانية والمستوى الدراسي لصالح طلبة السنة الثالثة والرابعة. وكذلك أظهرت النتائج وجود علاقة موجبة دالة بين سمة التسامح ونمط التعلق الأمن، ِِّحين لم تكن هناك علاقة بين سمة التسامح ونمط التعلق القلق

\title{
Prevalence of a Forgivingness Tolerance Trait among University Students and its Relationship with Attachment Styles
}

Ahmad M. Mahasneh*

Hashemite University, Jordan

\begin{abstract}
This study aimed to identify the prevalence of a forgiveness trait among university students and its relationship with attachment styles, and to determine any differences in the extent of forgiveness based on gender, academic specialization and academic level variables. Participants in the study consisted of 784 male and female undergraduate students at the Hashemite University in the academic year 2013-2014, who completed both the attachment styles and forgiveness traits scales. Results indicated a moderate prevalence of the forgiveness trait and no significant differences were found due to gender, while significant differences were found due to academic specialization in favor of humanist specializations and academic level in favor of third and fourth academic levels. Results also indicated that the secure attachment style indicated a positive relationship with the forgiveness trait, whereas no significant relationship was found between the anxious or avoidant attachment styles, and the forgiveness trait.
\end{abstract}

Keywords: Forgivingness trait, University students, attachment styles.

*dahmadmahasneh1975@yahoo.com 
يتضهن تخفيضا ِِّ دوافع شخصية معينة هي: الدافعية نحو تجنب الطرف المسيء، والدافعية نحو محاولة

الانتقام.

هنالك العديد من الأطر المفاهيمية للتسامح لدى الباحثين والدارسيـن. وقد ركز الكثير منهم على الطبيعة الترابطية لهذا المفهوم. حيث عرف كل من اينرايت، Enright, Santos \& Al-Mabuk, ) سانتوس والمابوك عهريك 1989) التسـامح على أنه القدرة على التغلب على العواطف السلبية وِ الحكم على الطرف المخطئ ، وذلك ليس عن طريق إنكار تلك الأحكام أو العواطف وإنها عن طريق تصور ذلك الطرف المخطئ بالشفقة والإحسان والحب. وبشكل مشابه لهذا التعريف، عرف كل من ينجر، Younger, Piferi, Jobe \& ) بايفيري، جوب ولولر لهنر

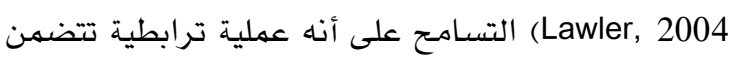
التخلص من المشناعر السلبية من أجل المحافظة على

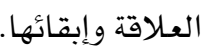

أما بعض الباحثين فقد عرفوا التسامح على أنه معتمد على الدافعية. فقد عرف كل كن من ماككولو، McCullough, Worthington \& ) وورثينجتونوراتشال (Rachel, 1997 التسامح على أنه مجموعة من التغييرات الدافعة يصبح الفرد خلالها أقل دافعية للانتقام من

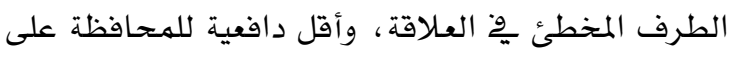
البعد مع المخطئ، وأكثر دافعية نحو المصالحة والنية الطيبة نحو الطرف المخطئ بالرغم من أفعاله المؤذية. أها كل من فينتشهام وباليريوريجاليا ) Fincham, Paleari \& فقد عرفوا التسامح انه تحول يتضهن (Regalia, 2002 نقصانا يخْ الدافعية نحو السعي للانتقام وتجنب مواجهة الطرف المخطئ، ويتضهن أيضا زيادة الدافع الإيجابي الاجتماعي نحو المخطئ. ويعرف والدرون وكيلي (Waldron \& Kelley, 2008) يستطيع من خلالها الأطراف المتألمة التتاقش والتقاوض بالتحسينات الممككنة لعدالة مشتركة وإيجاد حس جديد بالتقاؤل والحياة وبالتالي استعادة الود والثقة المفقودتين. ومن ابرز النظريات التي فسرت التسـاهح نظرية التحليل النفسي, حيث يؤكد فرويد على أهمية وجود ديناميات معينة ِِّ الشخصية تهارس تأثيرها وِّ سلوكياته
تعتبر الجامعة من أبرز وأهم المعاله ذات التأثير الاجتماعي هِّ المجتمع حيث تحتضن الشباب الجامعي ذوي الطاقات المتفجرة والههم العالية والخصائص النهائية التي تضفي أهمية بالفة على هذه المرحلة العهرية المتميزة ويهكن

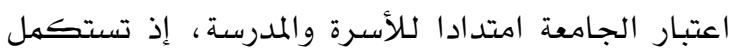

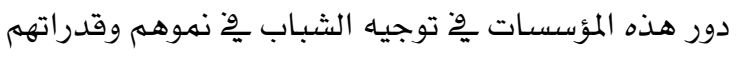
ومهاراتهم فضلا عن قيمهم واتجاهاتهم, كمها تعمل على دوره تحقيق تقدير الشباب لذواتهم.

إن سهة التسامح هـامة خاصة لطلبة الجامعة. حيث وجد كل من روهج وفينسترا (Romig \& Veenstra, 1998) أن ميل الفرد للتسامح مع الآخرين يرتبط بوجود حل لمشكلة متفاقمة. إن المهمة التطورية الرئيسية أثناء فترة الدراسـة الجامعية هي تطوير علاقات ودية مع الآخرين (Erikson, 1994)، وبالرغم من أن الخداع وفقدان تلك وئك

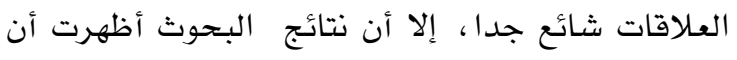

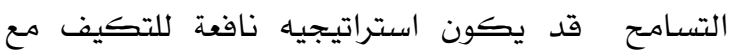
Rye \& Pargament, ) المشاكل التي تشوب تلك العلاقات 2002). والمهمة الأخرى التطورية لطلبة الجامعات هي التفرد وأن يصبح الطالب مستقلا عن عائلته من أجل أن يعزز ويقوي مفهوم الذات لديا. إن عملية التفرد هذه عادة

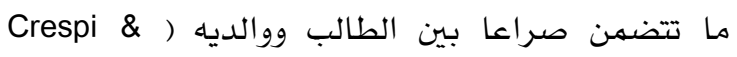
(Sabatelli, 1993 .ومن أجل بناء علاقات استقلالية. أصيلة مع الآباء بدلا من الانقطاع العاطفي عنهم يجب أجل

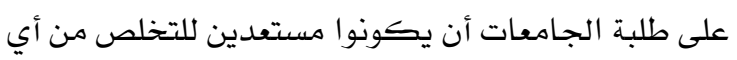
شعور بالكره أو الغضب من آبائهم. بمعنى آخر، يحتاجون أن يتعلموا كيف يسامحون من أجل حل أي مشكلة متفاقهة مِّ تلك المرحلة ( Al-Mabuk, Enright \&

(Cardis, 1995

من غير السهل أن نجد تعريفا واحدا للتسـامح. قدم كل من وورثنجتونوويد (Worthington \& Wade, 1999) تمييزا ببين التساهم وعدم التسامح. حيث يعتبر عدم التساهح عاطفة باردة يسودها الاستياء، والمرارة وربها الكراهية, وكذلك محاولة تجنب الطرف المخطئ أو المسيء. أما التساهـ فهو خيار الضدحية الداخلي (سواء كان قصديا أو غير متعهد) بترك عدم التسـامح والسعي السي للمصالحة مع الطرف المسيء. اقترح كل من ماككولو

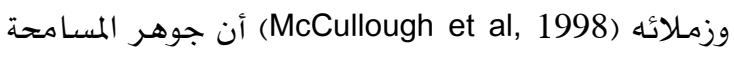


هنالك مدخلان رئيسيان لتصور مفهوم التسامح. المدخل

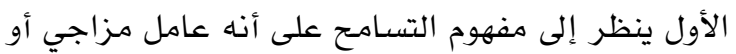

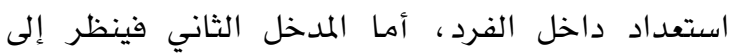

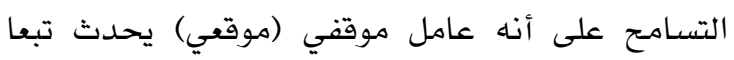
لحدث عدواني معين ) Eatona, Struthers \& Santelli, 2006; De Shea, 2007 علىأنه سهة التسامح (Trait Forgiveness)، أما الثاني فتم تعريفه على أنه حالة التسامح (State Forgiveness).

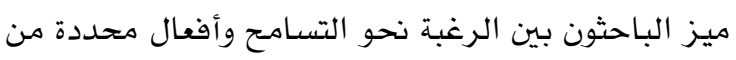

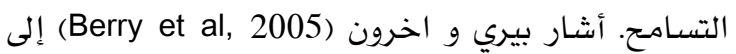

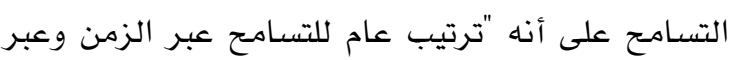

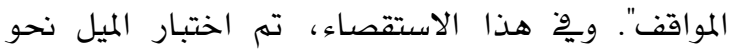

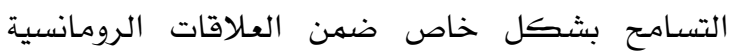
وبالتالي تم تعريفه على أنه ميل نحو غفران ذنب الآخرين المتجاوزين عبر الزمن ومن خلال المواقف. بالرغم من أنه مرتبط بالتسامح، إلا أن الميل نحو الففران ليس مساويا

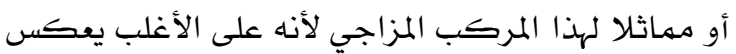
تاريخا مع الشخص بالإضافة إلى أي ترتيب للتسامح معاه.

وكذلك ميز كل من باسكن وانرايت ( Baskin \& (Enright, 2004 يركز قرار التسامح على بنية المعرفة, وأشار إليه الفيلسوف نيبلت (Neblett) الذي قال إن جوهر التسامح يكمن بِّْ قرار المسـامحة مع إطلاق العبارة "أنا سامحتك".

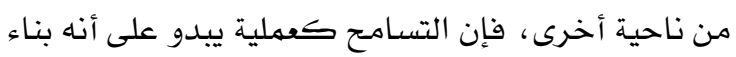

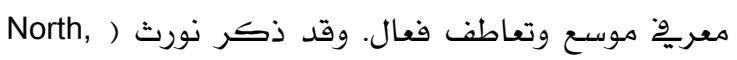

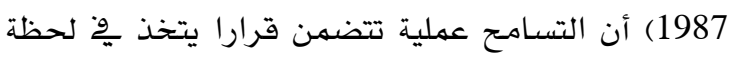

اقترح العديد من الباحثين أن الميل للتسامح يرتبط سلبيا

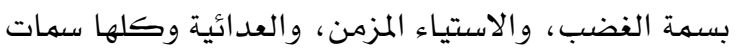

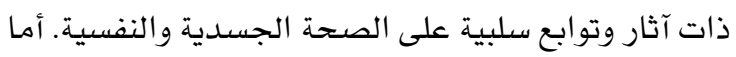
الدراسات التجريبية فقد دعمت العلاقة بين أفعال الفرد Huang \& ( التسامحية وانخفاض نسبة الغضب لديه Enright, 2000; Weiner et al, 1991 Ashton et al, ) أيضا أن التسامح يرتبط سلبيا بالعصابية عملئ 2000

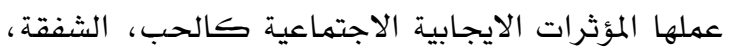

المختلفة. ويبرز فرويد أهمية اللاشعور وِّهم مختلف جوانب الشخصية بها فيها التسامح الذي يهكن تفسير نموه وارتقائه ِِّ ضوء بعض المكيانزمات مثل التسامي والتكوين العكسي (Sublimation) (عيدي، ·(Y). أما أصحاب النظرية السلوكية فيعتقدون أن التسامح يكتسب من خلال عمليات الاشتراط والتعزيز والملاحظة, فهو يتم من خلال تعلم

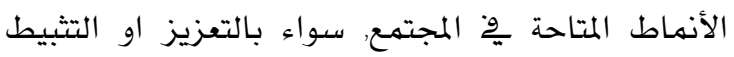

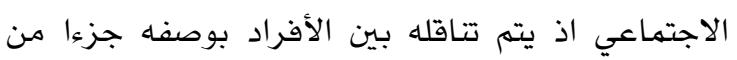
المصلحة الكبرى لمعايير الثقافة (Bandura, 1983).

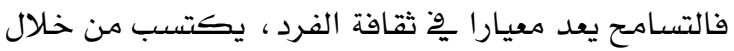

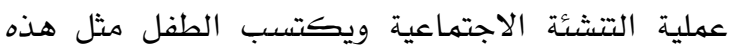
المعايير ويستجيب طبقا لها كي يشعر انه مقبول من قبل الآخرين, وهكذا تتتقل هذه المعايير بين الأفراد

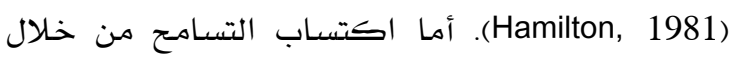

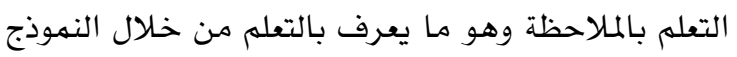

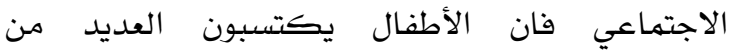
السلوكيات من خلال التفاعل مع والديهم, فالوالدان الدان

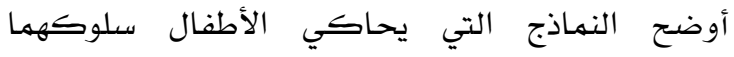
ويتوحدون معها منذ فترات العمر المبكرة فإذا ما كان كان التهان

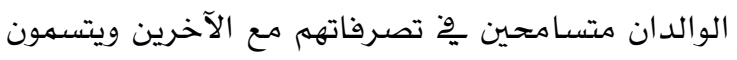

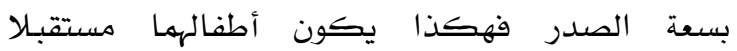

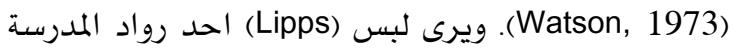

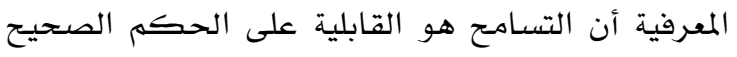

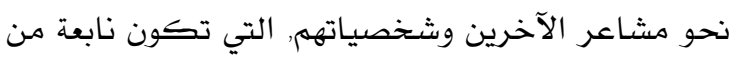
التعاطف معهم، أو هو استجابة تلقائية للإنشارات

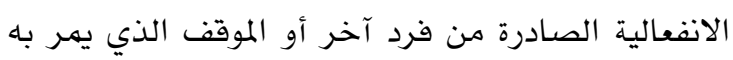

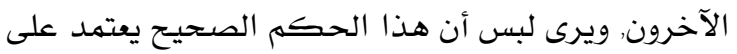

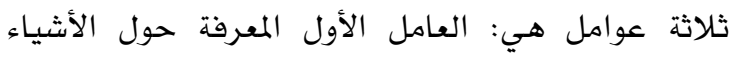

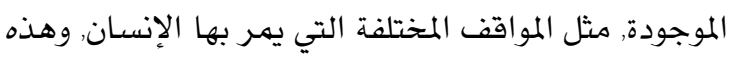
المعرفة تكون صادرة من الإدراك الحسي الموجود لدينا.

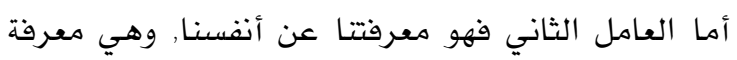

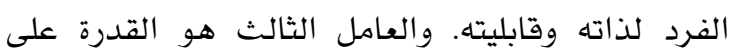
الحكم الصحيح على شخصية ومشاعر الأفراد الآخرين,وتكون نابعة من قابلية الفرد عل اخذ دور الأفراد الآخرين (Albort, 1960). 
الأطفال ومتطلباتهم النمائية. ويفترض بولبيأن أنماطا للتعلق تأخذ بِّ2 التشكل, منها ما هو أمن مطمئن لمصدر الرعاية (Secure attachment), ومنها ما هو غير أمن هن وغير مطهئن لذلك المصدر (Insecure attachment).

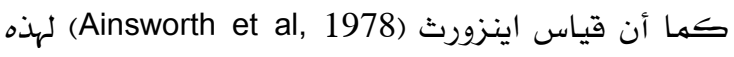
الأنماط كشف عن وجود نمط ثالث سمي النمط انش

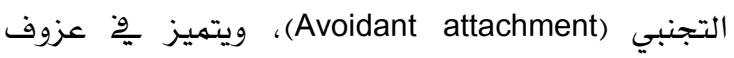

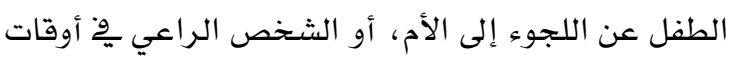
الضيق.

وقد تعددت التفسيرات النظرية فيما يخص أسباب نشوء الرابطة التعليقية، فبعض العلماء يعتقدون أنها مرتبطة

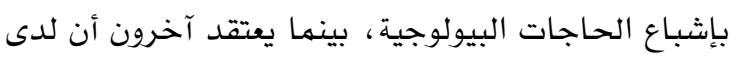
الطفل نزعه فظرية لتشكيل هذه العلاقة، فنظرية التحليل النفسي أرجعت جذور التعلق إلى الحاجات

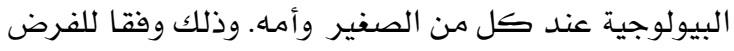

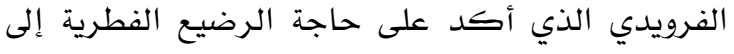

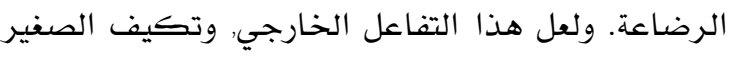

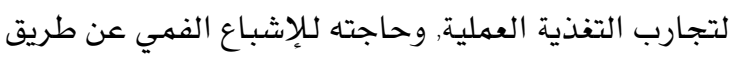

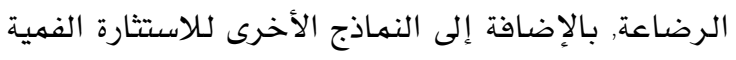

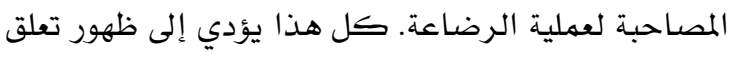

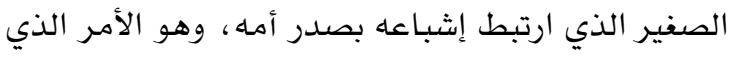

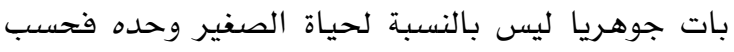

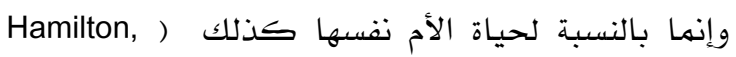
. (2000

وتؤكد النظرية الأخلاقية (Ethological Theory) على

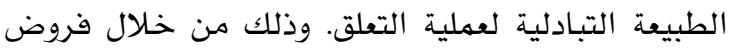
نظرية بولبي الأخلاقية عن التعلق (Bowlby, 1973). التي لتئي

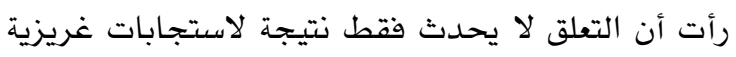

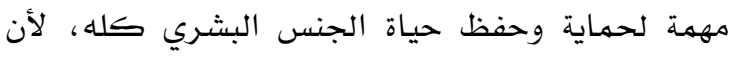

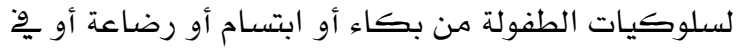

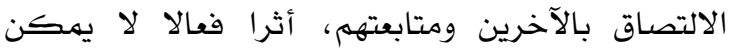

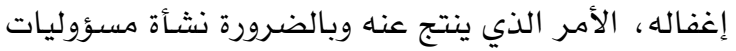

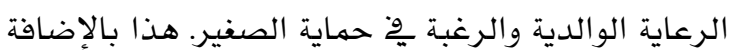
إلى أن ذلك قد يؤدي إلى الارتقاء بهستوى عمليات

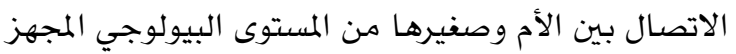

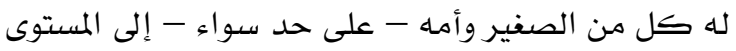

الثقة، التعاطف، أو العطف على الطرف المخطئ (Worthington \& Wade, 1999)

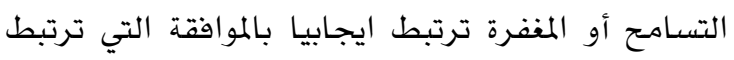

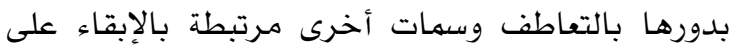
روابط شخصية إيجابية بين الأشخاص. وقد وجد اشتون

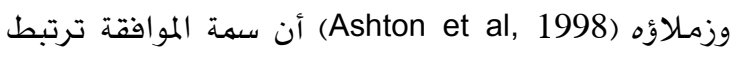

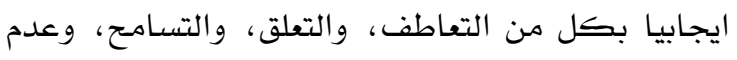

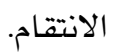
أها المتغير الثاني من متفيرات الدراسة فهو أنماط التعلق.

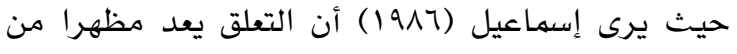

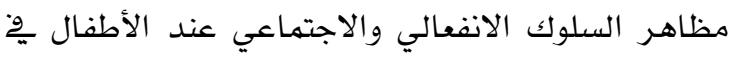
المراحل الأولى من العمر. ولعله لا توجد عملية أخرى أشد الشد الأفي

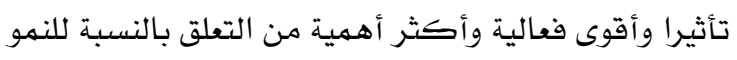

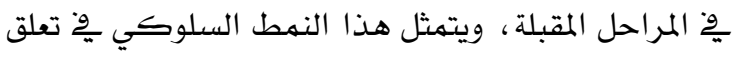
الطفل بالشخص الذي يحضنه الذي يحتل لديه المكانة الأولى, وخاصة لو كان هذا الشخص هو امه. ويعرف التعلق بأنه رابطة انفعالية قوية تؤدي إلى شعور

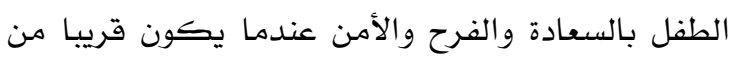

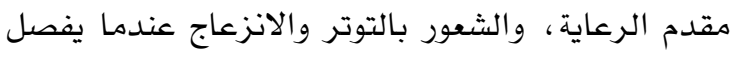

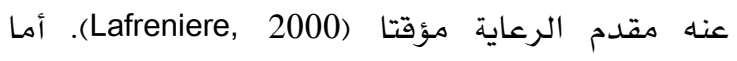
اينزوورث (Ainsworth, 1989) فيعرفه بأنه رابطة انفعالية

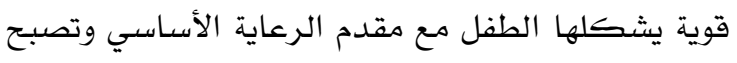

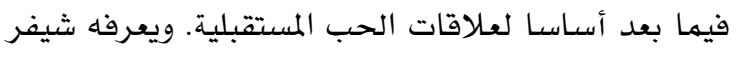
بأنه علاقة عاطفية قوية بين شخصيين تتميز (Sahver) بالتبادل العاطفي والرغبة وِّ المحافظة على القرب بينهما (Sahver and Brennan, 1992)

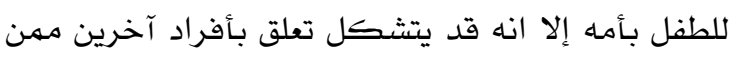

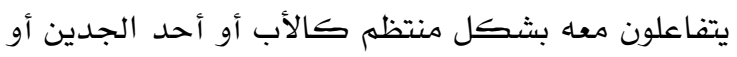

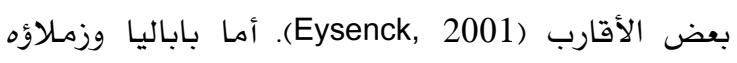
فقد أكدوا ِِّ2 تعريفهم للتعلق (Papalia et al, 1999) مساهمة كل من الطفل ومقدم الرعاية يِّ نوعية رابطة التعلق فعرفوه بأنه رابطة انفعالية قوية ومتبادلة بين

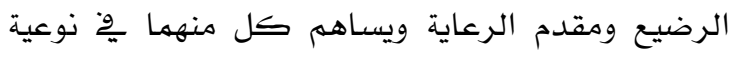
التعلق.

وتتمايز أنماط الأطفال التعلقية بتمايز واختلاف استجابات الأشخاص الذين يقومون على رعايتهم لحاجات 
الذين لديهم تعلق امن يهتلكون عدائية أقل وغضبا أقل مقارنة مـع الأفراد الذين لديهم تعلق غير امن. والسبب ِّن ذلك أن التخلص من الغضب يعتبر مكونا رئيسا للتسامح فهن الممكن أن يكون من السهل على الأفراد الذين

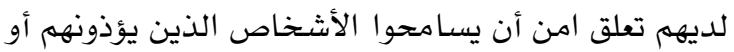
يضايقونهم (Enright \& Fitzgibbons, 2002). وحديثا قامت العديد من الدراسات التجريبية وبشكل مباشر بفحص العلاقة بين التسـامح والتعلق. وقد أظهرت نتائج تلك الدراسـات أن الأفراد ذوي نهط التعلق الأمن حققوا مستويات تسامح أعلى أكثر من الأفراد ذوي نهط التعلق Burnette, Taylor, Worthington, \& Forsyth, ) غير الأمن 2007; Davidson, 2001; Lawler-Row, Younger, Piferi \& Jones, 2006; Webb, Call, Chickering,

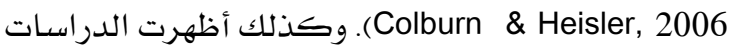
أن نمط التعلق القلق والتجنبي يرتبطان بشكل سلبي

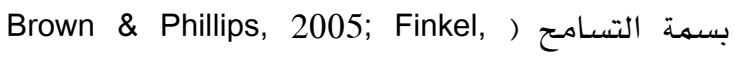
(Burnette \& Scissors, 2007 وكذلك فقد أظهرت نتائج الدراسـات أن إحدى المتفيرات التي ترتبط بالتسـاهـ هي أنماط تعلق الراشدين. فالأفراد ذوو نهط التعلق الأمن هم أكثر استعدادا لأن يحافظوا على ديمومة العلاقة ومواجهة الصراعات أو الخلافات ومن ثم التسامح (Lawler-Row et al, 2006). أما الأفراد ذوي التعلق غير الأمن فإنهم يتوقعون معتقدات أكثر Hazan \& ) سلبية حول الحب، ولديهم تعاطف أقل ،(Shaver, 1987; Feeney, Noller \& Callan, 1994

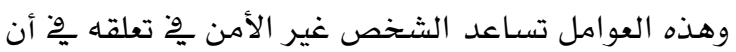
لا يكون متسامحا (Burnette et al, 2007). وقد أشـار McCullough, Worthington \& ) ماككولو وزملاؤه (Rachal, 1997 إلى أن التسـامح يتطلب تطوير تصور ذهني أكثر تعقيدا عن الطرف الآخر (الطرف المتجاوز) بحيث لا نعود نتصوره كشخص مثالي وإنها كفرد يمتلك كل من القدرات الايجابية والسلبية. وكل تلك التصورات المعقدة قد يكون من الصعب تطويرها لدى

$$
\text { الأفراد ذوي نمط التعلق غير الأمن. }
$$

دعمت العديد من نتائج الدراسـات العلاقة القائمة بين نهط التعلق والاستعداد للتسامح مع شريك رومانسي بعد
الأخلاقي والإنساني يِّ كل عمليات التشئة الاجتماعية للصغير.

وتعد نظرية بولبي (Bowlby, 1988) الأيثولوجية وجهة نظر مقبولة بِ الوقت الحاضر إذ إنها أكدت فكرة أنصار مدرسة التحليل النفسي، من حيث إن نوع التعلق مع مقدم الرعاية له تضهينات عميقة وههمة لشعور الطفل بالأمن وقدرته على تشكيل علاقة مفعهة بالثقة وتهتاز نظرية بولبي عن النظريات الأخرى، التي فسرت التعلق، بتركيزها على الدور النشط الذي يؤديه الطفل حديث الولادة بِّْ نشـوء هـذه العلاقة.

وبناء على افتراض استمـرارية أنهاط التعلق، يرى هـازان وشيفر (Hazan and Shaver, 1987) أن مشاعر الفرد وسلوكياته وأفكاره وِّ العلاقات الرومانسية ، تخضع لعمليات التعلق بمقدم الرعاية ِِّ مرحلة الطفولة ولاختبار هذه الفكرة قاما ببناء مقياس لأنهاط التعلق بِّْ مرحلة الرشـد، يعكس الأنهاط الأسـاسية للتعلق هي: التعلق الأمن (Seacure Attachment)، يسهل على أفرد هذا النمط الاقتراب من الآخرين، والثقة بهم والاعتماد عليهم، ويشعرون بالارتياح لأن الآخرين يثقون بهم أيضا

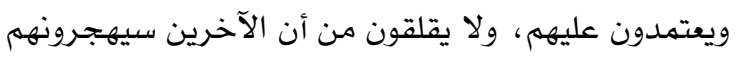
وسيتخلون عنهم، كما أنهم لا يقلقون من اقتراب

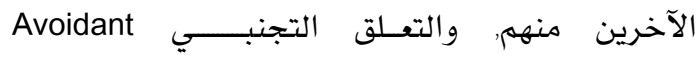

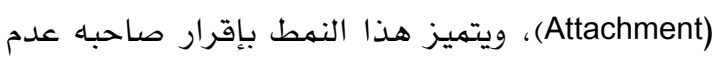
شعوره بالارتياح لبقائه قريبا من الآخرين، ويصعب علية الثقة بهم والاعتماد عليهم، ويشعر بالقلق عندما يقترب منه شخص ما كثيرا, والتعلق القلق المتتاقض وجدانيا (Anxious-Ambivalent Attachment) هذا النمط بأن الآخرين يرفضون الاقتراب منهم، ويشعرون بالقلق لأن نظراءهم لا يهتمون بهم، على الرغم من أن لديهم الرغبة بأن يكونوا قريبين جدا من نظرائهم.

إن الأدب التربوي أظهر وجود علاقات محتملة بين التعلق والتسـاهح. على سبيل المثال، اقترح هيل (Hill, 2001) أن التعلق المبكر بالآخرين قد يكون واحدا من العوامل

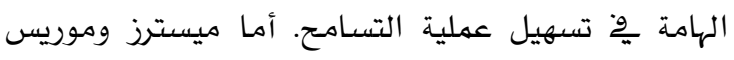
فقد لاحظا أيضا أن الأفراد (Meesters \& Muris, 2002) 
لدى عينة من طلبة الجامعات وكليات المجتمع. وقدأظهرت نتائج الدراسة أن الطلبة ذوي التعلق الأمن

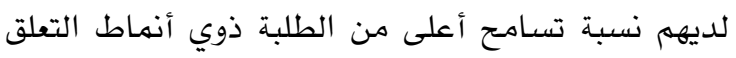

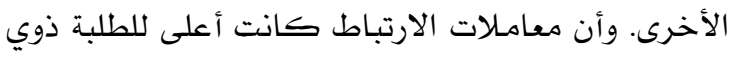

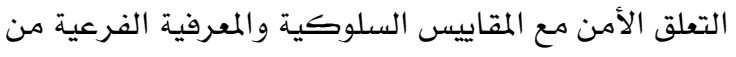

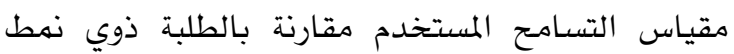

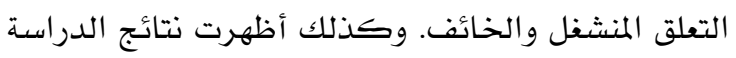

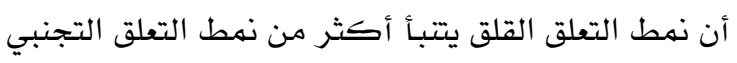
بسمة التسامح.

وكذلك قام بلونت -ماتيوس ( Blount-Matthews, ونات 2004) بدراسة أسفرت نتائجها عن وجود ارتباط موجب ودال إحصائيا بين نمط التعلق الأمن وسمة التسامح.

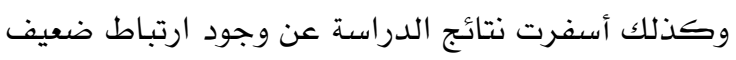

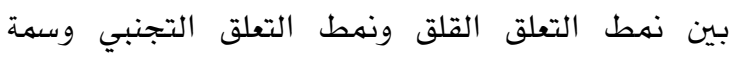
التسامح.

Mikulincer, ) قام كل من ميكلانكرووشيفير وسلوف

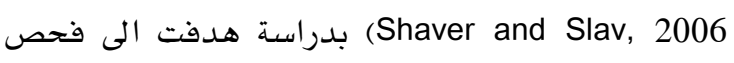
العلاقة بين أنماط التعلق وسمة التسامح. وتكونت عينة

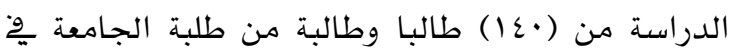
اسرائيل, واستخدم فيها مقياسين للتسامح, ومقياس لأنماط التعلق لدى طلبة الجامعة يوٌ إسرائيل. وقد أظهرت نتائج الدراسة أن الارتباط كان متوسط إلى منخفض بين

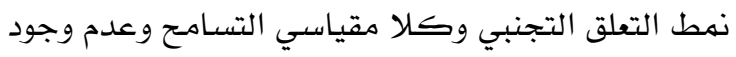

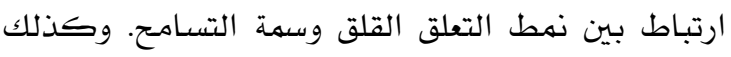

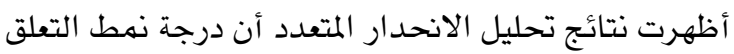

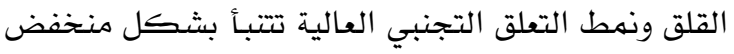

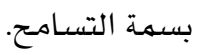
وقام فونكنون (Vuncannon, 2006) بدراسة هدفت

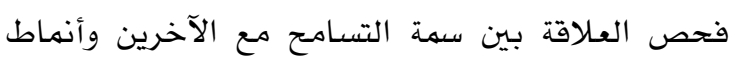

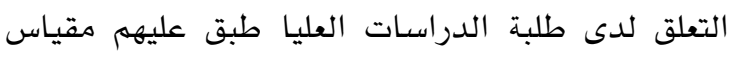
لأنهاط التعلق ومقياس سمة التسامح مع الآخرين. وقد لتد

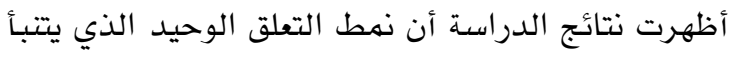

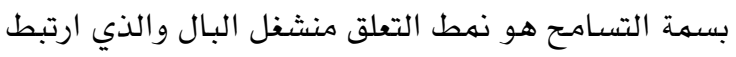
بهستويات عالية بسهة التسامح. وكذلك قام وانغ (Wang, 2008) بدراسة هدفت إلى الى فحص العلاقة بين أنماط التعلق وسمة التسامح لدى عينة
حدوث خلاف. على سبيل المثال، قام لوليرو وزملاؤه (Lawler-Row et al, 2006) والمسامحة للشريك ضمن علاقة قوية فيها قرب. وقدأظهرت نتائج الدراسة أن اليافعين ذوي التعلق الأمن أظهروا حالات وسمات تسامح أكبر استجابة لحالتي

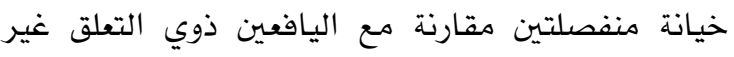

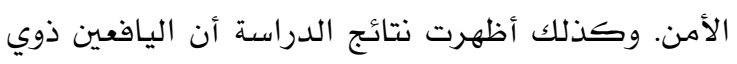

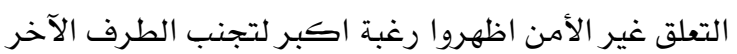
بعد الحادثة. و هِّْ دراسة ويب وزملاؤه (Webb et al, 2006) التي

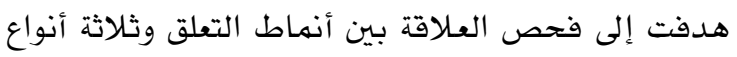

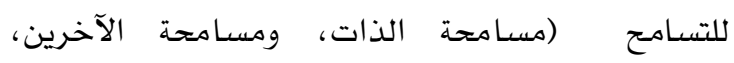

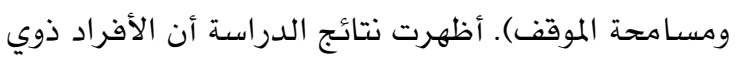

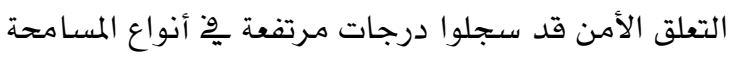

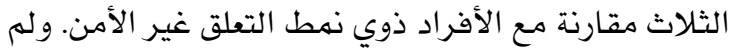
يكن هنالك علاقة ارتباطية بين أنماط التعلق الخائفالرافض والمشغول وأنواع المسا محة الثلاث.

وقد أظهرت الدراسات أيضا أن أنماط التعلق مرتبطة

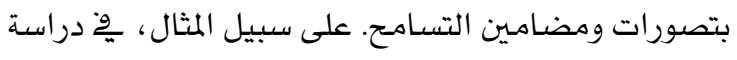

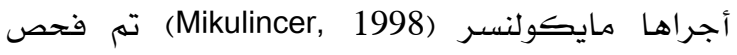
الاختلافات بِّ أنماط التعلق المنسوبة إلى النوايا العدائية

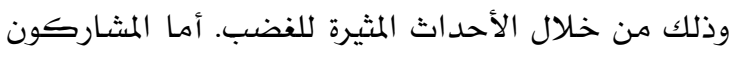
فقد تم تصنيفهم حسب نمط التعلق إلى قلقين وتجنبيين وآمنين وتم تعريضهم لسيناريوهات افتراضية مثيرة للغضب متباينة وِّ نوايا الطرف أو الشريك الرومانسي

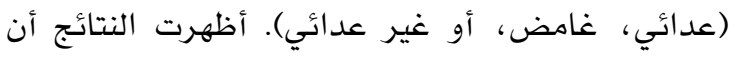

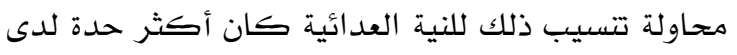

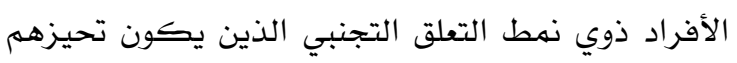

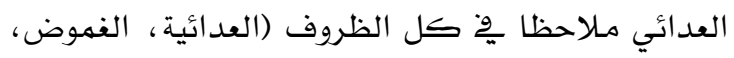
غير العدائية). وان الأفراد ذوي التعلق القلق فإنهم ينسبون النية العدائية أكثر پِّ كل من حالات (العدائية والغهوض)، بينها الأفراد ذوي التعلق الأمن فأنهم ينسبون

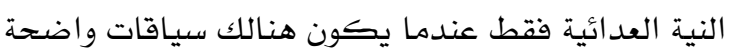
وِّْ حالة العدائية. وقام ديفيدسون (Davidson, 2001) بدراسة هدفت إلى فحص العلاقة الارتباطية بين أنماط التعلق وسمة التسامح دائح 
من أنجع الوسائل والسبل لتسهيل عملية المسامحة. وإدراكا لأهمية دور الجامعة يخّة هذه المرحلة العمرية لفئة الشباب الجامعي, الذين هم ِِّ مرحلة النضـ, وتولد الاتجاهات والميول والانتماءات الفكرية, حيث يمثلون

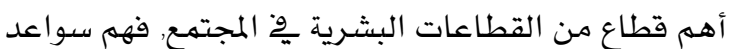
البناء وقادة المستقبل. وتتمثل مشكلة الدراسة الحالية فِ تحديد مستوى شيوع سمة التسامح لدى طلبة الجامعة ِوض الأردن بِّ ضوء بعض المتفيرات وفحص العلاقة بين سمة التساهح وأنهاط التعلق لديهم. وبشكل أكثر تحديدا تتحصر مشكلة الدراسة فِّ الإجابة عن الأسئلة الآتية:

السؤال الأول: ما مستوى شيوع سمة التسامح لدى طلبة الجامعة؟ - الجمان

السؤال الثاني: هل يختلف شيوع سمة التسامح لدى طلبة الجامعة باختلاف متغير (الجنس, والتخصص الاكاديمي. والمستوى الدراسي)؟

السؤال الثالث:هل توجد علاقة دالة إحصائيا بين كل من أنماط التعلق (الأمن, القلق, التجنبي) وسمة التسامح؟ أهمية الدراسة

للدراسة الحالية أهمية نظرية وعملية على حد سواء. فتكمن أهمية الدراسة الحالية النظرية ِِّ أهمية محاور الموضوع الذي تتتاوله بالدراسة، إذ إنها تسعى إلى استقصاء طبيعة العلاقة بين سمة التسامح وأنماط تعلق

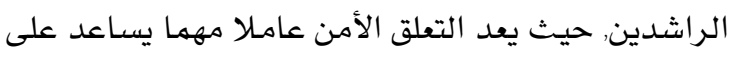
التوافق والصحة النفسية. وكذلك تكمن اهمية هذه الدراسة بِّ إثراء البحوث ِِّ هذا المجال والتحقق فيها إذا كانت هناك نتائج مشابهة لما توصلت إليه الدراسات ِوْ الدول الغربية حيث أن سمة التسامح ِِّ البيئة العربية تختلف عن سمة التسامع ِوْ البيئة الغربية وهذا قد يكون له الأثر الكبير يٌٌ طبيعة أنهاط التعلق.

أها الأهمية التطبيقية لهذه الدراسة فإن البحث ِوْ مجال التسامح وأنماط تعلق الراشـين يساهم ويساعد العاملين عِّ مجال الإرشاد الأسري والإرشاد النفسي والتربوي إلى بيان طرق وأسـاليب تعديل أنهاط التعلق خاصة وأن هناك توجهات حديثة للعلاج المبني على التعلق يْ علاج الكثير

$$
\text { من الاضطرابات النفسية. }
$$

من طلبة الجامعة ِوْ تايون (Taiwan)، وتكونت عينة الدراسة من (r.Y) من الطلبات الإنات و (YY) من الطلبة الذكور وكان متوسط أعمارهم (19) سنة طبق عليهم مقياس للتسامح ومقياس لأنهاط التعلق (الاعتمادي، القلق، والقريب). وقد أظهرت نتائج الدراسة أن أنماط التعلق ترتبط بسمة التسامح. وكذلك أظهرت نتائج الدراسـة أن نهط التعلق القلق والقريب يتتبأن بسمة التسـامح. قام جاسن ولينجل (Gassin and Lengel, 2011) بدراسـة هدفت إلى فحص العلاقة بين نهطي التعلق القلق والتجنبي وسمة التسامح. وتكونت عينة الدراسة على إلى طالبا وطالبة من طلبة الجامعة طبق عليهم مقياس (VV) لأنهاط التعلق ومقياس سمة التسامح. وأظهرت نتائج الدراسة أن نمط التعلق التجنبي يرتبط بسمة التسامح أكثر من نهط التعلق القلق.

يلاحظ من خلال استعراض نتائج الدراسـات السـابقة التي تتاولت العلاقة بين أنهاط التعلق وسمة التسـامح تتاقض نتائجها, إذ أشارت بعض نتائج بعض الدراسـات الى أن الأفراد الذين لديهم تعلق أهن أكثر ميلا إلى التسـامح من الأفراد الذين لديهم تعلق غير أمن, ووجود علاقة موجبة بين نهط التعلق الأمن وسمة التسامح كما هو ِوْ دراسـة Burnette, Taylor, Worthington, \& Forsyth, 2007; ) Davidson, 2001; Lawler-Row, Younger, Piferi \& (Jones, 2006; Webb, الدراسات الى وجود علاقة بين نهطي التعلق القلق والتجنبي وسمة التسامح كما هو دراسة ( Brown \& Phillips, 2005; Finkel, Burnette \& Scissors,2007; Mikulincer, Shaver and Slav, 2006; Gassin and Lengel, 2011 . ويلاحظ من خلال استعراض الدراسـات السابقة أن كل الدراسات أجريت پِّ دول غربية وندرة الدراسات التي أجريت ِِّ دول عربية وعليه فان ما يميز الدراسة الحالية عن الدراسـات السابقة هو إجرائها على إنى عينة من طلبة الجامعات الأردنية. مشككلة الدراسة

تعتبر الجامعة من أهم المؤسسات التربوية والتعليمية ِوِ تعزيز سمة التسـامح لدى الطلبة, حيث إن التربية والتعليم 


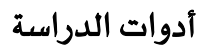

تم تطبيق مقاييس المتغيرات التي تعنى بها الدراسة وهي:

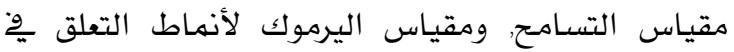
مواقف صفية جمعية من قبل الباحث لجميع الشعب التي لئرفي

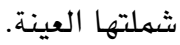

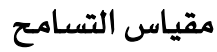

تم استخدام مقياس التسامح الذي أعده ري واخرون Rye, Loiacono, Folck, Olszewski, Heim \& Madia, ) 2001), ويتكون المقياس من (10) فقرة لقياس سمة (10)

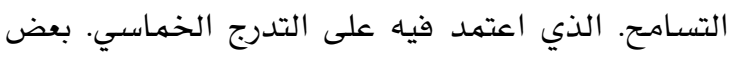

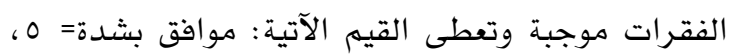

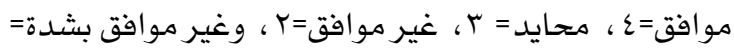
1. ويعكس التدرج للقيم السلبية. ويهكن لدرجة المفحوص أن تتراوح ما بين 10 -VO درجة تعكس

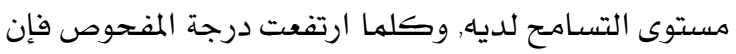

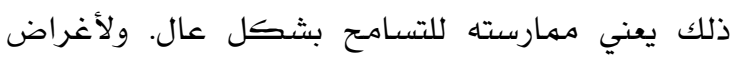
الدراسة الحالية قام الباحث بترجمة المقياس من اللفة الانجليزية إلى اللفة العربية وبعد ذلك تم عرض الترجمة على ثلاثة من المتخصصين بِّ قسم اللفة الانجليزية للتأكد من دقة الترجمة ووضوح الفقرات ومقروئيتها وملاءمتها للفرض الذي أعدت له. وتم إجراء التعديلات

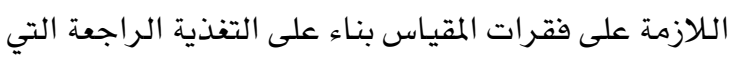
تم الحصول عليها. وبعد ذلك قام الباحث بعرض الصورة الاصلية للمقياس والصورة المعربة للمقياس على ستة من

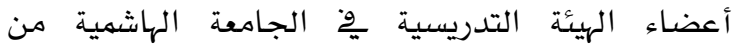

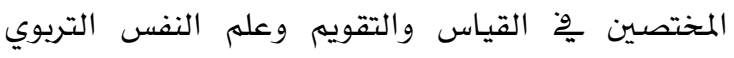

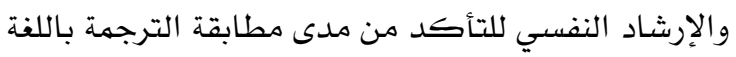

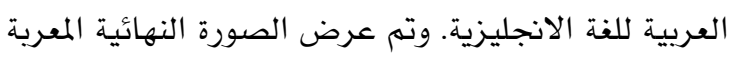

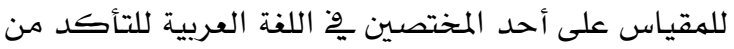
سلامة الصياغة وسلامة اللغة.

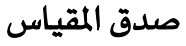
للتأكد من صدق المقياس اتبع الباحث ما يلي:

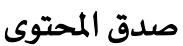
للتأكد من صدق المحتوى للمقياس عرضت فقرات

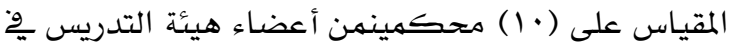

التعريف الإجرائي للمتغيرات

التسامح: عملية ترابطية تتضمن التخلص من المشاعر السلبية من أجل المحافظة على العلاقة وإبقائها (Younger, Piferi, Jobe \& Lawler, 2004) إجرائيا بالدرجة التي يحصل عليها الطالب عل مقياس سمة التسامح المستخدم ِِّ الدراسة الحالية.

التعلق: رابطة انفعالية قوية يشكلها الطفل مع مقدم

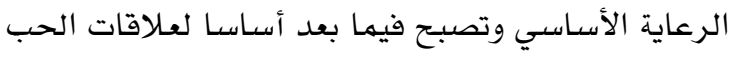
المستقبلية (Ainsworth,1989)، ويعرف إجرائيا بالدرجة التي يحصل عليها الطالب عل مقياس انماط التعلق المستخدم يِّ الدراسة الحالية.

\section{الطريقة والإجراءات}

\section{مجتمع الدراسة وعينتها}

تألفت مجتمع الدراسة من الطلبة المسجلين لدرجة

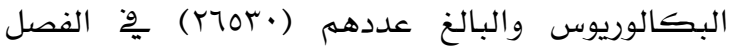

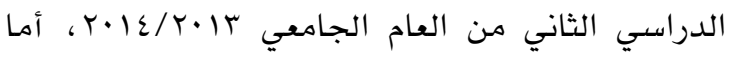

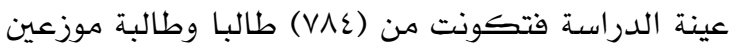

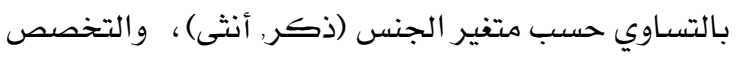

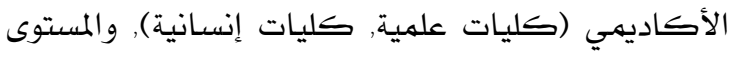
الدراسي (سنة أولى, سنة ثانية, سنة ثالثة, سنة رابعة). وقد اختير هؤلاء الطلبة بالطريقة المتيسرة من خلال اختيار أريع شعب من متطلبات الجامعة الاختيارية. ويوضح جدول ا توزيع أفراد العينة تبعا لمتفيرات الدراسة.

جدول المبال

توزيع أفراد عينة الدراسة تبعا لمتغيرات الدارسة

\begin{tabular}{|c|c|c|c|}
\hline النسبة المئوية & العدد & المستوى & المتغير \\
\hline$\%$ \% Q.r & rNt & ذكور & الجنس \\
\hline$\% \circ . . v V$ & ra人 & إناث & \\
\hline 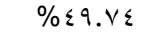 & rq. & علمية & الكلية \\
\hline$\% 0 . . r 4$ & raई & إنسانية & \\
\hline \%५०.r人 & 199 & سنة أولى & المستوى \\
\hline$\% \curlyvee \leq . \wedge \vee$ & 190 & سنة ثانية & الدراسي \\
\hline \%ro.vv & $r \cdot r$ & سنة ثالثة & \\
\hline$\%$ \%r.q1 & 14 & سنة رابعة & \\
\hline $1 \ldots \ldots$ & $\vee \wedge \varepsilon$ & & المجموع \\
\hline
\end{tabular}


ويتكون المقياس من (·r) فترة, تتم الإجابة عنها من خلال أسلوب ليكرت ذي التدرج الخهاسي, بحيث يهثل

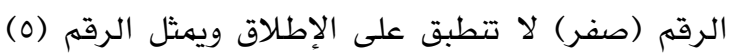

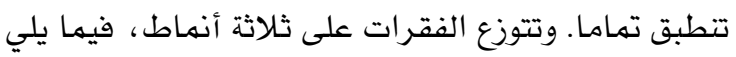
وصف لها: نهط التعلق الأمن (Secure Attachment Style): يظهر هذا النمط إلى أي درجة ينظر الفرد بشكل إيجابي إلى نفسها والى الآخرين. ويتكون هذا النمط من (7) فقرات.

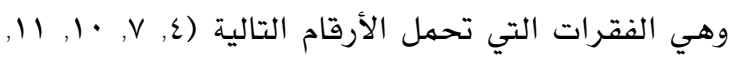
ع 1, 9 ) )، وتتراوح الدرجات عليه من (•) إلى (•r). Anxious-Ambivalent Attachment ) نهط التعلق القلق Style : يظهر هذا النهط إلى أي درجة ينظر الفرد بشكل سلبي إلى نفسه وبشكل إيجابي إلى الآخرين. ويتكون هذا النمط من (V) فقرات. وهي الفقرات التي تحمل

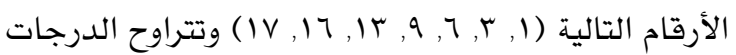

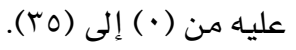

نهط التعلق التجنبي (Avoidant Attachment Style): يظهر هذا النهط إلى أي درجة ينظر الفرد بشكل إيجابي إلى نفسها وبشكل سلبي للآخرين. ويتكون هذا النهط من (V) فقرات. وهي الفقرات التي تحمل الأرقام التالية:

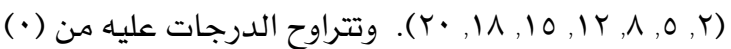

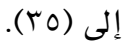

\section{صدق المقياس}

تم إجراء صدق محتوى لمقياس التعلق, بعرض المقياس على ستة محكمهين من أعضاء هيئة التدريس ِّْ قسم علم النفس الإرشادي والتربوي پِّ جامعة اليرموك، وقد أعيدت صياغة ثلاث فقرات بناء على رأي بعض المحكهـين، ولهم يكن هناك مـلاحظات لديهم حول انتماء كل فقرة لنمط التعلق الذي تمثله إضافة إلى ذلك, تم استخدام أسلوب التحليل العاملي وفقا لطريقة المكونات الأساسية، وأجري التدوير باستخدام طريقة التدوير المتعامد . وبينت نتائج التحليل وجود V+ عوامل كان الجذر الكامن لكل منها > 1, وتقسر بهجموعها

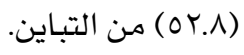

كلية العلوم التربوية بالجامعة الهاشهية لإبداء آرائهم ِ2ْ فقرات المقياس من حيث سـلامة اللفة ووضوحها, وقدرتها على قياس سمة التسامح ومـلائمة مقياس تدريج الفقرات, حيث تم تعديل بعض الفقرات التي اقترح المحكمون

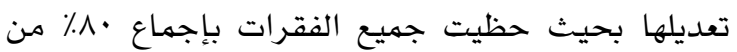
المحكمـين. صدق البناء: تمر التأكد من صدق بناء المقياس حيث تم حساب معامـلات الارتباط بين فقرات المقياس والمقياس ككل حيث تراوحت معاملات الارتباط ما بين .$(\cdot .70-\cdot . r \varepsilon)$ ثبات المقياس

تم حساب معامل الثبات (الاستقرار) للهقياس ككل بطريقة الاختبار وإعادة الاختبار بفاصل زمني مقداره

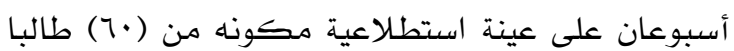
وطالبة من طلبة الجامعة الهاشمية. وبلفت قيمة معامل الارتباط بين مرتي التطبيق للمقياس ككل (10.•). كما تم حساب معامل الاتساق الداخلي (كرونباخ الفا) للمقياس ككل وبلفت (VA.•). تصسيح المقياس

لجأ الباحث إلى تقسيم المتوسطات الحسابية لإجابات أفراد عينة الدراسـة عن مقياس سهة التساهح إلى ثلاثة مستويات متسـاوية حسب المعيار التالي:

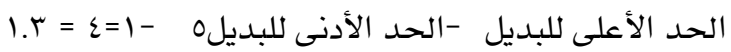

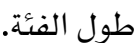
عدد المستويات = r r

وبذلك تكون درجة شيوع التسامح منخفضة 1

وتكون درجة شيوع التسامح متوسطة من سب.r+r

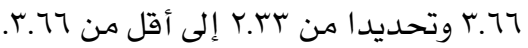

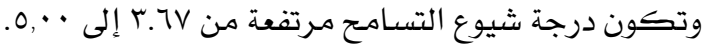

مقياس اليرموك لأنماط التعلق

قام بإعداد هذا المقياس كل هن ابو غزال وجرادات (Y. (Y) وقد أسمياه "مقياس اليرهوك لأنماط التعلق" 
القلق من 9 فقرات, والتجنبي أيضا من (9) فقرات، وِ

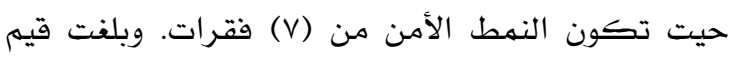
معامل الثبات لكل نهط من هذه الأنماط على النحو لتحن

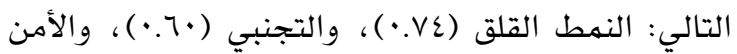

بالإضافة إلى ذلك،قام ابو غزال وجرادات (Y.9.9)

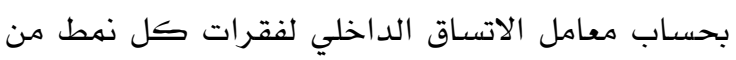
هذه الأنماط, بعد تطبيق المقياس على العينة الكلية للدراسة وإجراء تحليل عاملي له، وتم حذف (0) فقرات منه بناء على نتائج هذا التحليل. وقد بلفت قيم معامل

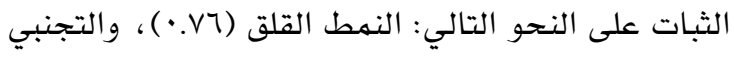

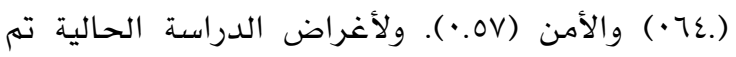
التحقق من ثبات المقياس تم حساب معاملات ثبات

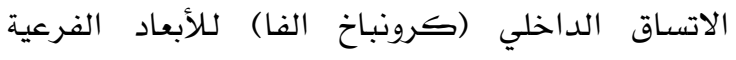

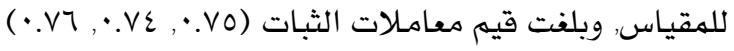

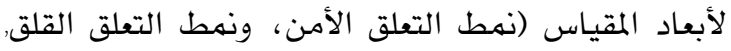
ونهط التعلق التجنبي) وتعد معاملات ثبات مقبولة.

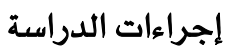

بعد استخراج دلالات صدق وثبات أداة الدراسة, شرع الباحث بتنفيذ إجراءات التطبيق حيث قام بتوزيع الأدوات التات الترات على أفراد عينة الدراسة بِّ مواقف صفية جمعية ، حيث

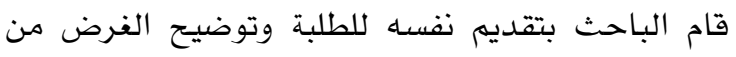
الدراسة وأهميتها وتعليمات الإجابة على أدوات الدراسة.

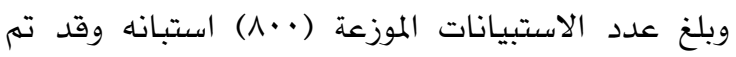
استبعاد (17) استبانه لعدم إكمال الطلبة المعلومات

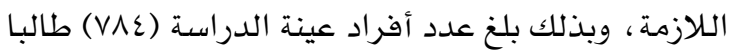
وطالبة. وتم تطبيق الأساليب الإحصائية المناسبة للإجابة المرادية عن أسئلة الدراسة. و وتئ.
وقد أشـارت معاملات ارتباط بيرسـون إلى أن النمط الأمن ارتبط عكسيا بشكل دال بالنهط القلق وايجابيا بشكل دال بالنهط التجنبي, ولم يظهر هناك ارتباط دال

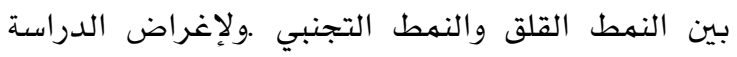

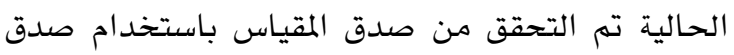

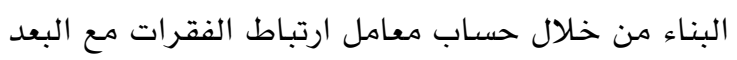

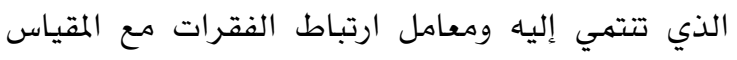

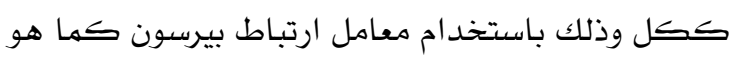

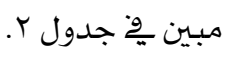
يلاحظ من جدول r أن قيم معاملات الارتباط لفقرات

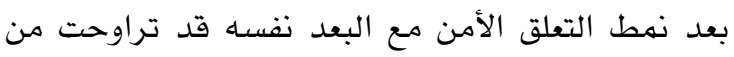

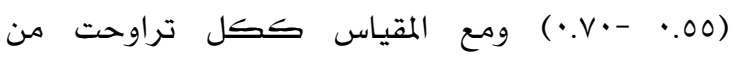

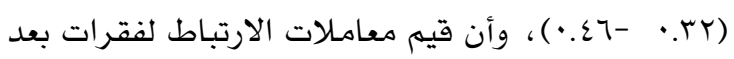

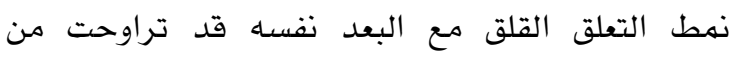

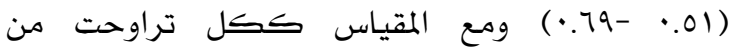

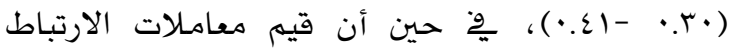
لفقرات بعد نهط التعلق التجنبي مع البعد نفسه قد اند

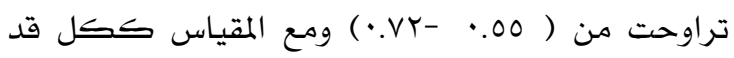

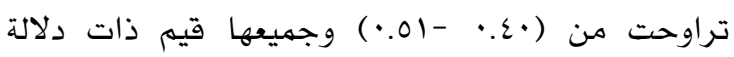

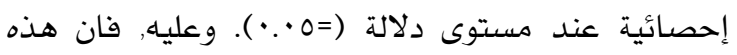
النتائج تعزز صدق البناء للمقياس، وتشير إلى أن فقرات المقياس تقيس ما أعدت لقياسه.

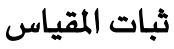

تم التحقق من ثبات مقياس التعلق من خلال تطبيقه على

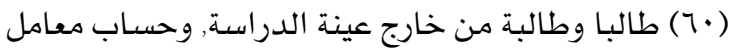
الاتساق الداخلي باستخدام معادلة كرونباخ ألفا لفقرات

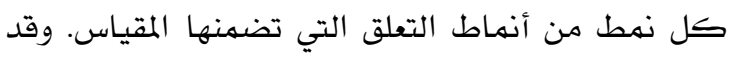

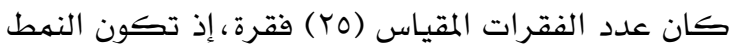

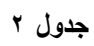

\section{معاملات الارتباط بين الارجات على كل فقرة من فقرات المقياس ككل والأبعاد الفرعية}

\begin{tabular}{|c|c|c|c|c|c|c|c|c|}
\hline \multirow[b]{2}{*}{ المقياس } & \multicolumn{2}{|c|}{ نمط التعلق التجنبي } & \multicolumn{4}{|c|}{ نمط التعلق القلق } & \multicolumn{2}{|c|}{ نمط التعلق الأمن } \\
\hline & البعد & الفقرة & المقياس & البعد & الفقرة & المقياس & 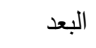 & الفقرة \\
\hline$* . \varepsilon$ & $*$ * . & r & *.ro & $* .7 \leq$ & 1 & $* . . \leqslant r$ & $* .77$ & $\varepsilon$ \\
\hline * . . &.$V Y$ & 。 & $* . r \Lambda$ & $* .79$ & $r$ & * * & $* .00$ & V \\
\hline$* . \leqslant 0$ &. .71 & $\wedge$ & " * & $* .7 r$ & 7 & $* . r \leq$ & $* . V$ & 1. \\
\hline$* .01$ & .77 & Ir & * & $* .0 r$ & 9 & $* . r \leq$ & $* .71$ & 11 \\
\hline$* . . \leqslant \varepsilon$ & .00 & 10 & $*$ *. & $* .01$ & M & $* . . \leq 7$ & $* .01$ & $1 \varepsilon$ \\
\hline$* .01$ &. .01 & 11 & " * ש & $* .77$ & 17 & $* . r r$ & $* .00$ & 19 \\
\hline *. . . $\leqslant \leq$ & .79 & $r \cdot$ & $* . r$. & $* .01$ & iv & & & \\
\hline
\end{tabular}


جدولr

المتوسطات الحسابية والانحرافات المعيارية والمجموع الكلي لإجابات أفراد عينة الدراسة عن فقرات مقياس سمة التسامح

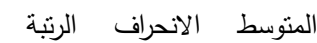

الحسابي المعياري

$10 \quad$ l.1 $10 \quad$ T.r

يصعب علي النوقف عن

التفكير حول ظلمي سابقا

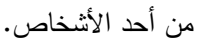

أتنىى حدوث أثنياء جيدة

لالثخاص الذين ظلموني.

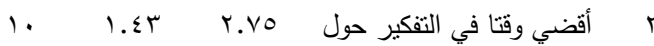

طرق عودتي إلى

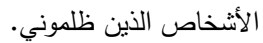

أشعر بالاستياء تجاه

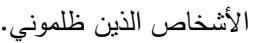

$9 \quad$ أتجنب أثخاص أو أماكن معينة لأنها تذكرني

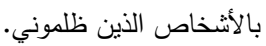

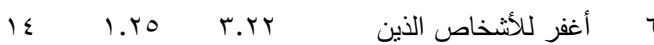
ظلموني.

أشعر بالهذوء إذا واجهت

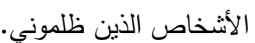

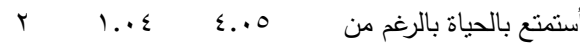

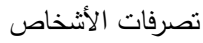

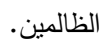

9 $\quad$ أتجاهل غضبي تجاه

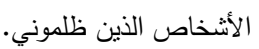

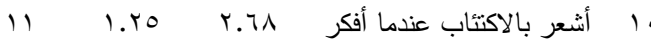
بسوء معاملة الأثخاص لي.

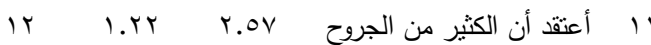

العاطفية المرتبطة بتصرفات

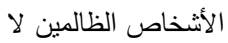

تلنئم.

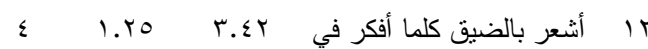

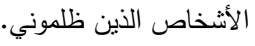

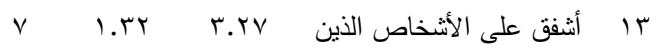

ظلموني.

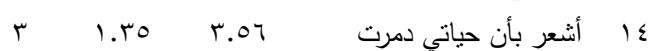

بسبب تصرفات الأثخاص داص دمرت

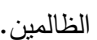

10

ظلموني أن يعاملوا الآخرين

معاملة عادلة في المستقبل.

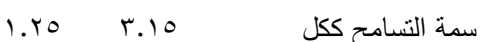

تصميم الدراسة

تعد هذه الدراسة من الدراسـات الوصفية الارتباطية.

التحليل الإحصائي

لتحليل البيانات ذات الصلة بأسئلة الدراسة فقد تم استخدام الأسـاليب الإحصائية الآتية:

إيجاد المتوسطات الحسابية والانحرافات المعيارية لكل فقرة من فقرات مقياس التسـاهح.

استخدام اختبار مريع كاي (Chi-Square) لتحديد الفروق يْ تقدير درجة التسـامح لدى أفراد عينة الدراسـة تبعا لمستوى المتغيرات المستقلة. كما تم استخدام معامل ارتباط بيرسون لإيجاد العلاقة بين سمة التسامح وأنهاط

التعلق.

\section{النتائج ومناقشتها}

فيما يلي عرض لنتائج الدراسـة وفقا لأسئلتها :

\section{النتائج المتعلقة بالسؤال الأول: "ما مستوى شيوع سمة \\ التسامح لدى طلبة الجامعة"؟.}

للإجابة عن هذا السؤال فقد تم حسـاب المتوسطات الحسابية والانحرافات المعيارية والمجموع الكلي لإجابات أفراد عينة الدراسة عن مقياس سمة التسـامح, وجدولr يوضح ذلك, وكذلك حساب التكرارات والنسب المئوية لمستوى شيوع سمة التسامح لدى أفراد عينة الدراسـة وجدولع يوضح ذلك.

يظهر من جدول ب أن المتوسطات الحسابية لإجابات أفراد عينة الدراسة عن فقرات مقياس سهة التساهح تراوحت

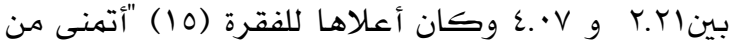
الأشخاص الذين ظلموني أن يعاملوا الآخرين معاملة عادلة

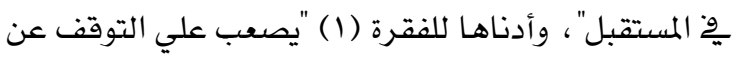
التفكير حول ظلهي سـابقا من أحد الأشخاص". وبلغ المتوسط الحسابي للمقياس ككل (10.10). ويبين جدول ع التكرارات والنسب المئوية لمستويات شيوع سمة التسـامـح لدى أفراد عينة الدراسـة. 
جدول

التكرارات والنسب المئوية وقيمة مربع كاي (Chi-square) ودلالته

\begin{tabular}{|c|c|c|c|c|c|}
\hline \multirow[t]{4}{*}{ المجموع } & \multicolumn{4}{|c|}{ مستويات شيوع سمة التسامح } & \multirow[t]{4}{*}{ الجنس } \\
\hline & منسامح & متسامح & متسامح & التكرارات & \\
\hline & بدرجة & بدرجة & بدرجة & و والنسب & \\
\hline & مرتفعة & متوسطة & منخفضة & & \\
\hline 广人T & 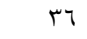 & q & 11 & 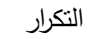 & ذكور \\
\hline$\cdots \cdots$ & $9 . r$ & $\wedge \vee . \wedge$ & r.9 & $\%$ & \\
\hline rqA & $\leq \wedge$ & TrV & ir & التكرار & إناث \\
\hline$\cdots \ldots$ & ir & $\Lambda \varepsilon . V$ & r. & $\%$ & \\
\hline$\vee \wedge \varepsilon$ & $\Lambda \leq$ & $T \vee 7$ & $r \leq$ & التكرار & المجموع \\
\hline $1 \ldots$ & $1 . . v \cdot$ & A५.r. & r.l. & $\%$ & \\
\hline
\end{tabular}

يظهر من جدول 0 عدم وجود اختلاف يٌٌ مستوى شيوع سمة التسامح باختلاف جنس الطالب, حيث بلغت قيمة مربع كاي (Chi-square) (ع •.V.V) وهي قيمة غير دالة إحصائيا عند مستوى دلالة (a=0 • • ). ويهكن أن يعزى ذلك إلى أن الطلبة (الذكور والإناث) يعيشون الواقع نفسـه والظروف ذاتها, وتشابه المجتمع الذي ينتمياليه الطلبة. بالإضافة إلى ذلك تعرض الطلبة جميعا ذكورا وإناثا إلى الظروف التعليمية نقسها ِخ الجامعة بسبب طبيعة التعليم المختلط, مها يجعلهم يتشربون القيم نفسها ومنها قيمة التسـامح. وتتفق هذه النتيجة مع نتائج دراسة Barber, Maltby \& Macaskill, 2005; Brown \& ) (Phillips, 2005; Toussaint \& Webb, 2007 توصلت إلى عدم وجود فروق بين الجنسسين ِِّ سمة التسـامح. جدول التكرارات والنسب المئوية وقيمة مربع كاي (Chi-square) على مستوى جلى

\begin{tabular}{|c|c|c|c|c|c|}
\hline \multirow[t]{3}{*}{ المجموع } & \multicolumn{4}{|c|}{ مستويات شيوع سمة التسامح } & \multirow[t]{3}{*}{ 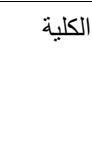 } \\
\hline & بدرجة & بدرجة & بدرجة & التكرارات & \\
\hline & مرتفعة & متوسطة & منخفضة & والنسب & \\
\hline rq. & os & rrs & ir & التكرار & 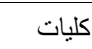 \\
\hline$\cdots \ldots$ & 1 IT.人 & Ar.l & r.l & $\%$ & علمية \\
\hline rqs & 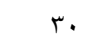 & ror & ir & 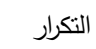 & 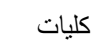 \\
\hline$\ldots \ldots$ & $V .7$ & ᄉ9.r & r.l & $\%$ & إنسانية \\
\hline$\vee \wedge \varepsilon$ & $\Lambda \leq$ & 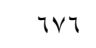 & $r \leq$ & التكرار & 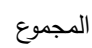 \\
\hline$\ldots \ldots$ & $1 . . v$. & Aт.Y. & r.). & $\%$ & \\
\hline
\end{tabular}

يظهر من جدول 7 وجود اختلاف ِِّ شيوع سمة التسـامح Chi-) باختلاف تخصص الطالب, حيث بلغت قيمة
جدول

التكرارات والنسب المئوية لمستويات شيوع سمة التسامـح لاى جلى

\begin{tabular}{|c|c|c|}
\hline النسب المئوية & 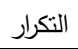 & مستوى شيوع سمة التسامح \\
\hline$\%$ \%.। & $r \varepsilon$ & متسامح بدرجة منخفضة \\
\hline$\% \wedge \neg$. \ & TV & متسامح بدرجة متوسطة \\
\hline$\% 1 \cdot . v$ & $\Lambda \varepsilon$ & متسامح بدرجة مرتفعة \\
\hline $1 \ldots$ & $\vee \wedge \leq$ & المجموع \\
\hline
\end{tabular}

يظهر من جدول ع أن أعلى نسبة مئوية لتوزيع أفراد العينة على مقياس سمة التسـامح بلغت (YT.Y) للتسـامح بدرجة متوسطة, تليها النسبة المئوية (l.V) للتسـامح بلدرجة مرتفعة, بينما بلغت أدنى نسبة مئوية (1.) للتساهـ بدرجة منخفضة. ويهكن تفسير هذه النتيجة يو ضوء المرحلة العمرية لطلبة الجامعة اذ يمتاز الطلبة نوعا ما بالنضـج والاتزان الانفعالي والهدوء والقدرة على تحمل الضغوط. بالإضافة إلى ذلك يهكن عزو هذه النتيجة إلى نمذجة طرق التعامل من قبل أعضاء الهيئة التدريسية فِ الجامعة مع طلبتهم إذ أن طبيعة تعاهل أعضاء الهيـة التدريسية مع الطلبة يوٌ الجامعة تقوم على أسـاس التسـاهـ والصبر والتحمل وهذا ما ينعكس ايجابيا على شيوع سهة التسامح لدى الطلبة أنفسهم. وعلاوة على ذلك يهكن تقسير هذه النتيجة يخ ضوء طرق التدريس المتبعة يٌْ الجامعة الهاشمية والتي تقوم على المناقشـة والحوار والعمل التعاوني والابتعاد عن التقلين مِ التدريس مها يجعل الطلبة يتقبلون وجهات نظر الآخرين وتحمل سوء التصرف الذي قد يواجهونه أحيانا. وهن وجهاه أخرى، يهكن عزو هذه النتيجة أيضا إلى أن أكثر أنماط التتشئة الأسرية شيوعا يوّ المجتمع الأردني وهو النهط الديعقر اطي الذي يعزز قيم التسـاهـ والتقبل.

النتائج المتعلقة بالسؤال الثاني: "هل يختلف شيوع سمة التسامح لدى طلبة الجامعة باختلاف متغير (الجنس,

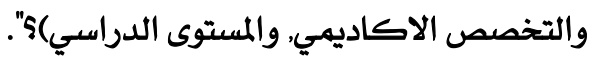
للإجابة عن هذا السؤال تم حساب التكرارات والنسب المئوية لمستويات شيوع سهة التسامح لدى أفراد عينة الدراسة تبعا لمتفيرات الجنس،والتخصص الاكاديهي، والمستوى الدراسي، وتطبيق اختبار مربع كاي (Chi-) وجدول 0 توضت ذلك. (square 
هذه الدراسة نتائج الدراسـات السابقة ( Cheng \& Yim, 2008; Hui et al. 2006; Orathinkal, Vansteenwegen (\& Burggraeve, 2008; Wallker \& Gorsuch, 2002 التي وجدت أن سهة التساهـح تزداد هع تقدم الأفراد بالعمر. جدول التكرارات والنسب المئوية ونتائج تطبيق اختبار (Chi-square) على ل

\begin{tabular}{|c|c|c|c|c|c|}
\hline \multicolumn{5}{|c|}{ وع سمة التساميح تبعا لمتغير المستوى الدراسي } & \multirow{4}{*}{ 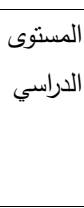 } \\
\hline & \multirow{3}{*}{ مدرجة منسامح } & \multirow{3}{*}{ منسرجة منسمة } & \multirow{3}{*}{ مندرجة منسامح } & \multirow{3}{*}{ والنسب - ارات } & \\
\hline & & & & & \\
\hline & & & & & \\
\hline 199 & rq & 100 & $\Lambda$ & التكرار & السنة \\
\hline $1 \ldots \ldots$ & 11.1 & VV. 9 & $\varepsilon$ & $\%$ & الأولى \\
\hline 190 & 17 & IVT & 7 & التكرار & السنة \\
\hline $1 \ldots \ldots$ & A.r & 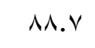 & r. 1 & $\%$ & الثانية \\
\hline$r \cdot r$ & $r$. & $1 V \varepsilon$ & $\wedge$ & التكرار & السنة \\
\hline $1 \ldots$ & 9.9 & 人..) & $\varepsilon_{.}$ & $\%$ & الثالثة \\
\hline 111 & ir & IVE & r & التكرار & السنة \\
\hline $1 \ldots \ldots$ & T. & 9..० & 1.1 & $\%$ & الرابعة \\
\hline$V \wedge \varepsilon$ & $\Lambda \varepsilon$ & TVY & $r \varepsilon$ & التكرار & المجموع \\
\hline $1 \ldots \ldots$ & $1 . . v$. & Nז.Y. & r.l. & $\%$ & \\
\hline
\end{tabular}

النتائج المتعلقة بالسؤال الثالث: "هل توجد علاقة دالة إحصائيا بين سمة التسامح وأنماط التعلق (الأمن, القلق,

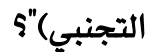
للإجابة عن هذا السؤال, تم حسـاب معامل ارتباط بيرسون بين سمة التسامح من جهة وأنهاط تعلق الراشدين من جها

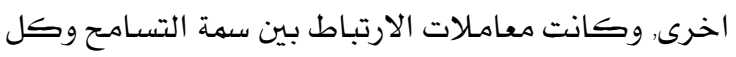
من نهط التعلق الآمن ونهط التعلق القلق ونهط التعلق

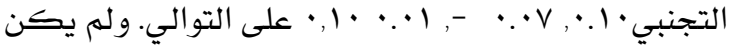
دالا إحصائيا إلا معامل ارتباط التسامح بنهط التعلق الآمن. ويهكن أن تقسر هذه النتيجة بان الأفراد ذوي التعلق الآمن يتعاطفون مع الطرف المسيء ويحاولون فهم أوضاعهم, بالإضافة إلى أن الأفراد ذوي التعلق الأمن لديهم تصور إيجابي للذات وللآخرين, وكذلك فإن الأفراد ذوي التعلق الأمن يستخدمون استراتيجيات من أجل الحصول على المساعدة والدعم العاطفي والاجتماعي من أجل الحد من الفضب والمشثاعر السلبية من خلال التأكيد على ديهومة العلاقات الحميهمة والعاطفية مع مع الحمن الأفراد الآخرين. بالإضافة إلى ذلك, يميل الطلبة ذوي نهط
(V.99V) (square

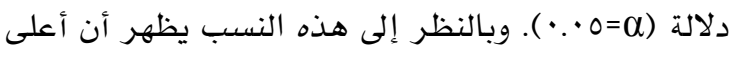
نسبة شيوع سهة التساهـ بدرجة متوسطة كانت لدى طلبة الكليات الإنسانية. ويهكن أن تفسر هذه النتيجة بان طبيعة المقررات والمنهاج وِّ الكليات الإنسانية والتي تزود الطلبة بالمعلومات والمعارف والمفاهيم والخبرات الدينية ، وبالتالي تعمل هذه المقررات على تشريب الطلبة القيم وتعزيزها لديهم, بينما تقتصر الكليات العلمية على قدر محدود من المساقات والمقررات ذات الصلة بالقيم باستثناء القليل من متطلبات الجامعة الاختيارية. كما أن من فرول طبيعة المقررات ِّْ الكليات الإنسانية ذات طوابع تريوية وإنسانية واجتماعية، على العكس من المقررات العلمية التي يغلب عليها التعامل مع القضايا المادية (الحسية). بالإضافة إلى ذلك،اختلافطرق التدريس التي تقوم عليها التخصصات،فعادة ما تدرس المساقات ِِّ الكليات الإنسانية بطرق تختلف عن تدريس المساقات يوٌ الكليات العلمية، إذ غالبا ما تدرس المساقات ِّو الكليات الإنسانية بلعب الدور، والتعلم التعاوني، والتدريس غير المباشر، وهي طرق غالبا غير متبعة ِِّْ تدريس مساقات التخصصات العلمية.

يظهر من جدولV وجود اختلاف ِِّ شيوع سهة التسامح باختلاف المستوى الدراسي للطالب, حيث بلغت قيمة مريع كاي ATV. ·r وهي قيمة دالة إحصائيا عند مستوى دلالة (0=0=0 • • ). وبالنظر إلى هذه النسب يظهر أن أعلى نسبة لشيوع سمة التسامح كانت لدى طلبة السنة الثالثة والسنة الربعة, تليها نسبة شيوع سمة التسـامح لدى طلبة السنة الثانية وٌِّ المرتبة الأخيرة نسبة شيوع سمة التسامح لدى طلبة السنة الأولى. ويمكن أن تفسر هذه النتيجة إلى أنه كلما تقدم الطلبة ِِّ المستوى الدراسي تقدموا بالعمر, وبالتالي يكون الطلبة أكثر نضجا ووعيا، فيدرك أن سهة التسامح ضرورية للإبقاء على العلاقات الاجتماعية مع الآخرين. ويهكن تفسير هذه النتيجة أيضـا, بسبب طبيعة الخبرات التربوية والاجتماعية التي قد التح يتعرض لها الطلبة نتيجة التحاقهم بالجامعة ، إذ يتعرض طلبة السنتين الثالثة والرابعة إلى خبرات أكثر كما ونوعا مقارنة مع طلبة السنتين الأولى والثانية. وتتقق نتائج 


$$
\begin{aligned}
& \text { ا. ضرورة العمل على ترسيخ سمة التسـامح لدى الطلبة } \\
& \text { من خلال برامج موجهه، وخطط عملية. } \\
& \text { r. تضهمين سهة التسامح ِِّ المساقات والمقررات }
\end{aligned}
$$

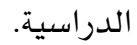

r. إجراء دراسـات أخرى تهدف إلى فحص العلاقة بين

سمة التسامح وسمات الشخصية الخمس الكبرى.

ع. إجراء دراسات أخرى تهدف إلى التعرف على اثر

أنماط المعاملة الوالدية على سهة التسامح.

$$
\text { المراجع }
$$

\section{References}

ابوغزل، معاوية ، وجرادات، عبدالكريم (9 ․ ب). أنماط تعلق الراشدين وعلاقتها بتقدير الذات والشعور

بالوحدة. المجلة الاردنية ِِّ العلوم التربوية، ه (1)، $.0 V-\varepsilon 0$

اسماعيل، محمد عماد الدين (1917). الأطفال مرآة المجتهم: النهو النفسي الاجتهاعي للطفل (يٌْ سنواته

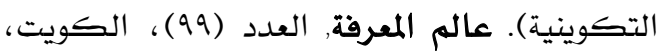
المجلس الوطني للثقافة والفنون والآداب.

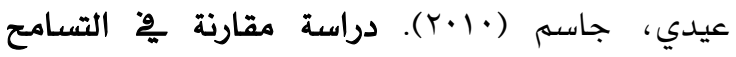
الاجتماعي وفقا لمستويات الذكاء الثقايخ لد طلبة الجامعة. (رسالة ماجستير غير منشورة)، الجامعة

$$
\text { المستصرية ، بغداد. }
$$

Ainsworth, M. D. S., Blehar, M. C., Waters, E., \& Wall, S. (1978). Patterns of attachment: A psychological study of the strange situation. Oxford, UK: Erlbaum.

Ainsworth, M. D. S. (1989). Attachments beyond infancy.American Psychologist, 44, 709-716.

Albort, G. (1960). Personality and social encounter. Beacon Press, Boston.

Al-Mabuk, R., Enright, R. D., \& Cardis, P. (1995). Forgiveness education with parentally love deprived college students.Journal of Moral Education, 24, 427444.
التعلق الأمن إلى الارتياح والرغبة ِِّ القرب من الآخرين، وحب الأفراد الآخرين, والثقة بهم, وهذه الصفات الهات تعد الصد

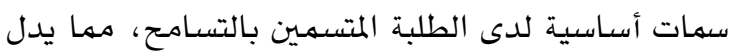
على وجود ارتباط بين سمة التساهح ونهط التعلق الأمن. وتتفق هذه النتيجة هـع نتائج الدراسات السابقة Davidson, 2000; Lawler-Row et al, 2006; Webb ) et al, 2006; Yaben, 2009 علاقة دالة إحصائيا بين نهط التعلق الأمن وسهة التسامح، وأن أنماط التعلق ترتبط باعتقادات الأفراد واتجاهـاتهم وخبراتهم بأنفسهم وبالآخرين. فالأفراد ذوي النماذج السلبية للآخرين لا لعاتهترثون بالآخرين ويرفضوههم، وعليه فتموذج الذات ونهوذج الآخرين تؤثر

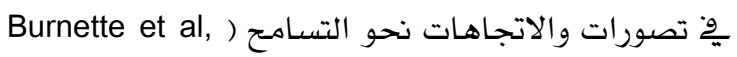
2007; Watt, McWilliams \& Campbell, 2005

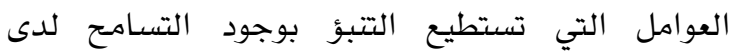
الأشخاص هي أسلوب التعلق لديهم والعلاقات الأساسية مع الآباء خلال فترة الطفولة. لذلك فان أنهاط التعلق قد الت تكون فعالة لفهم وتحديد الاختلافات بين الأشخاص. ويمكن الادعاء أيضا أن نظريتي التسامح و التعلق لهها نفس الأهمية. ويهكنتا القول حينها أن كلتا النظريتين مرتبطان بهفاهيم معينة مثل: الثقة، التعاطف، التواصل والتوازن العاطفي. بالإضافة إلى ذلك، فيان هـاتين النظريتين تعتبران مجموعة معقدة من التفيرات النفسية

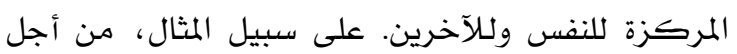
التسـامح فان الناس عادة يحتاجون أن يستجيبوا بطريقة تعاطفية وعليهم تجاهل الشك, والأحاسيس الفارغة والغضب والذنب، لذلك فإن نمط التعلق يعتبر واحدا من أهم العوامل پِّ التفاعلات الفردية التي تتشكل خلال فترة الطفولة وحسب البيئة التي تطورت فيها فإنها تستمر لباقي العهر. ويعتبر نهط التعلق أيضا رابطا عاطفيا عميقا يبنيه الشخص مع أشخاص معينين ِّ حياته, وبالتالي تجعلهم يشعرون بالسعادة والحيوية ِِ تلك العلاقات وعندما يتعرضون للقلق يكون بجانبهم.

التوصيات

ِّخ ضوء النتائج التي توصلت إليها الدراسة الحالية يوصي الباحث بها يلي: 
Ashton, M. C., Paunonen, S. V., Helmes, E., \& Jackson, D. N. (1998). Kin altruism, reciprocal altruism, and the Big Five personality factors.Evolution and Human Behavior, 19, 243-255.

Bandura, A. (1983). Psychological mechanisms of aggression. In R. G. Geen \& E. I. Donnerstein (Eds.), Aggression: Theoretical and empirical reviews (Vol. 1, pp. 1-40). San Diego, CA: Academic Press.

Barber, L., Maltby, J., \& Macaskill, A. (2005). Angry memories and thoughts of revenge: The relationship between forgiveness and anger rumination. Personality and IndividualDifferences, 39, 253-262.

Baskin, Thomas W. \& Enright, Robert D. (2004). Intervention studies on forgiveness: A meta-analysis. Journal of Counseling $\mathcal{E}$ Development, 82, 79-89.

Berry, J.W., Worthington, E.L., O'Connor, L.E., Parrott, L., \& Wade, N.G. (2005). Forgiveness, vengeful rumination, and affective traits.Journal of Personality, 73(1), 183-225.

Blount-Matthews, K. M. (2004). Attachment and forgiveness in human development: A multimethod approach. (Tesis de Doctorado no publicada), University of California, Berkeley, CA, EstadosUnidos.

Bowlby, J. (1973). Attachment and Loss: Separation (Vol. 2). New York: Basic Books

Bowlby, J. (1988). A secure Base: Clinical applications of attachment theory. London: Routledge.

Brown, R. P., \& Phillips, A. (2005). Letting bygones be bygones: further evidence for the validity of the tendency to forgive scale. Personality and Individual Differences, 38, 627-638.

Burnette, J. L., Taylor, K. W., Worthington, E. L., \& Forsyth, D. R. (2007). Attachment and trait forgivingness: The mediating role of angry rumination. Personality and Individual Differences, 42, 1585-1596.

Cheng, S., \& Yim, Y. (2008). Age differences in forgiveness: The role of future time perspective. Psychology and Aging, 23, 676680.

Crespi, T. D., \& Sabatelli, R. M. (1993). Adolescent runaways and family strife: a conflict-induced differentiation framework. Adolescence, 28, 867-878.

Davidson, L. L. (2001). Forgiveness and attachment in college students.Dissertation Abstracts International: Section B: The Sciences and Engineering, 61(11-B), 6129.

DeShea, L. (2007). Measuring forgiveness.In W. Malcolm, N. DeCourville, \& K.Belicki (Eds), Women's reflections on the complexities of forgiveness. New York: Routledge. Pp2138.

Eatona, J., Struthers, C. W., \& Santelli, A. G. (2006). Dispositional and state forgiveness: the role of self-esteem, need for structure, and narcissism. Personality and Individual Differences, 41, 371-380.

Enright, R.D., \& Fitzgibbons, R.P. (2002).Helping clients forgive: An empirical guide for resolving anger and restoring hope. Washington, DC: American Psychological Association.

Enright, R. D., Santos, E. M. J. D., \& Al-Mabuk, R. (1989).The adolescent as forgiver.Journal of Adolescence, 12, 95-110.

Erikson, E. (1994). Identity and the life cycle. New York: Norton.

Eysenck, M. W. (2001). Psychology, a student handbook.Psychology Press.

Feeney, J. A., Noller, P., \& Callan, V. J. (1994).Attachment style, communication and satisfaction in the early years of marriage. In K. Bartholomew, \& D. Perlman (Eds.), Attachment processes in adulthood. Advances in personal relationships, 5 (pp. 269-308). Bristol, PA: Jessica Kingsley Publishers.

Fincham, F. D., Paleari, F. G., \& Regalia, C. (2002). Forgiveness in marriage: The role of relationship quality, attributions, and empathy. Personal Relationships, 9, 27-37.

Finkel, E. J., Burnette, J. L., \& Scissors, L. E. (2007). Vengefully ever after: Destiny beliefs, state attachment anxiety, and forgiveness. Journal of Personality andSocial Psychology, 92, 871-886.

Gassin, E. A., y Lengel, G. J. (2011). Forgiveness and attachment: a link that survives the grave?.Journal of Psychology and Theology, 39, 316-329. 
Hamilton, D. L. (Ed.) (1981).Cognitive processes in stereotyping and intergroup behavior. (Hillsdale, NJ: Erlbaum).

Hamilton, C. (2000). Continuity and discontinuity of attachment from infancy through adolescence.Child Development, 71, 690-694.

Hazan, C., \& Shaver, P. (1987).Romantic love con- ceptualized as an attachment process.Journal of Personality and Social Psychology, 52, 511-524.

Hill, E. W. (2001). Understanding forgiveness as discovery: implications for marital and family therapy. Contemporary Family therapy, 23, 369-384.

Huang, S. T., \& Enright, R. D. (2000). Forgiveness and anger-related emotions in Taiwan: Implications for therapy. Psychotherapy: Theory, Research, Practice, Training, 37, 71-79.

Hui, E. K. P., Watkins, D., Wong, T.N.Y., \& Sun, R.C.F. (2006). Religion and forgiveness from a Hong Kong Chinese perspective.Pastoral Psychology, 55,183-195.

Lafreniere, P. (2000). Emotional development: A biosocial perspective. London: Wadsworth.

Lawler-Row, Kathleen A., Younger, Jarred W., Piferi, Rachel L., \& Jones, Warren H. (2006). The role of adult attachment style in forgiveness following an interpersonal offense. Journal of Counseling $\mathcal{E}$ Development, 84(4), 493-502.

McCullough, M. E. (2000). Forgiveness as human strength: Theory, measurement, and links to wellbeing. Journal of Social and Clinical Psychology, 19, 43-55.

McCullough, M. E., Rachal, K. C., Sandage, S. J., Worthington, E. L., Brown, S. W., \& Hight, T. L. (1998). Interpersonal forgiving in close relationships II: Theoretical elaboration and measurement. Journal of Personality and Social Psychology, 75, 15861603.

McCullough, M. E., \& Worthington, E. L., Rachal, K. C. (1997).Interpersonal forgiving in close relationships.Journal of Personality and Social Psychology, 73, 321-336.

Meesters, C., Muris, P. (2002). Attachment styles and self-reported
aggression.Psychological Reports, 90, 231235.

Mikulincer, M. (1998). Adult attachment style and individual differences in functional versus dysfunctional experience of anger. Journal of Personality and Social Psychology, 74(2), 513-524.

Mikulincer, M., Shaver, P. R., y Slav, K. (2006).Attachment, mental representations of others, and gratitude and forgiveness in romantic relationships.En M. Mikulincer y G. S. Goodman (Eds.), Dynamics of romantic love.Attachment, caregiving, and sex (pp.190215). New York: Guilford Press.

North, J. (1987). Wrongdoing and forgiveness.Philosophy, 62, 499-508.

Papalia, D., old S. and Feldman, R. (1999).A child's world: infancy through adolescence. New York: The McGraw-Hill company, Inc.

Romig, C. A., \& Veenstra, G. (1998). Forgiveness and psychosocial development: implication for clinical practice. Counseling and Values, 42, 185-199.

Rye, M. S., Lolacono, D. M., Folck, C. D., Olszewski, B. T., Heim, T. A., Madia, B. P. (2001).Evaluation of the psychometric properties of two forgiveness scales.Current Psychology, 20, 260-277.

Rye, M. S., \& Pargament, K. I. (2002). Forgiveness and romantic relationship in college: can it heal the wounded heart?.Journal of ClinicalPsychology,58, 419441.

Shaver, P. R., \& Brennan, K. A. (1992). Attachment styles and the 'Big Five' personality traits: Their connections with each other and with romantic relationship outcomes. Personality and Social Psychology Bulletin, 18, 536-545.

Toussaint, L., \& Webb, J. R. (2007). Gender Differences in the Relationship Between Empathy and Forgiveness. Journal of Social Psychology, 145(6), 673-685.

Vuncannon, J. W. (2006). The perceptions of attachment style and forgiveness in romantic couples (Doctoral dissertation).Regent University, Virginia Beach, VA.

Waldron, V. \& Kelley, D. (2008).Communicating forgiveness. Thousand Oaks, CA: Sage. 
Walker, D.F., \& Gorsuch R.L. (2002).Forgiveness within the Big Five personality model.Personality and Individual Difference, 32, 1127-1137.

Wang, T. W. (2008) Adult attachment and forgiveness in Taiwanese college student.Psychological Reports, 103,161-169.

Webb, M., Call, S., Chickering, S. A., Colburn, T. A., \& Heisler, D. (2006). Dispositional forgiveness and adult attachment styles.Journalof Social Psychology, 146(4), 509-512.

Weiner, B. A., Graham, S., Peter, O., \& Zmuidinas, M. (1991). Public confession and forgiveness.Journal of Personality, 59, 281-312.

Worthington, E. L., \& Wade, N. G. (1999). The social psychology of un-forgiveness and forgiveness and implications for clinical practice.Journal of Social andClinical Psychology, 18, 385-418.

Watson, P.(1973). Psychology and race. Aldine Publishing Company, Chicago.

Younger, J. W., Piferi, R. L., Jobe, R. L., \& Lawler, K. A. (2004). Dimensions of forgiveness: The views of laypersons. Journal of Social and Personal Relationships, 21(6), 837-855. 